\title{
Hazards of New Technology in Promoting Food Adulteration
}

\author{
Gautam Anita* \& Singh Neetu** \\ Research Scholar* \& Asst. Professor** \\ Department of Human Development \& Family Studies School for Home Sciences Babasaheb Bhimrao \\ Ambedkar University, Lucknow-226025 Uttar Pradesh, India
}

\begin{abstract}
Adulteration is the process by which the quality or the nature of a given substances is reduced through the addition of a foreign or an inferior substance and the removal of a vital element. And it's ugly face is come out in the form of it's harmful effects as stomach disorder giddiness and joint pain, diarrhea, liver disorder, dropsy, gastrointestinal problems, respiratory distress, oedema, cardiac arrest, glaucoma carcinogenic effects, paralysis etc. According to Singh, Anita; et al. (2011) milk is staple food for both the group of children urban as well as rural area. From both the regions a wide variation of adulterants mixing was observed which causes diarrhea eyesight problems headache etc. Kumar, Ashish. (2011) reviewed that adulteration were detected in milk to the tune of $70 \%$ with water, turmeric powder-43\% with chalk powder, red chilli powder-100\% with artificial color, sugar 37\% with chalk powder. Khapre,M.P.,2011 found that 68.5\% Households, wife (home-maker) buys the grocery. Majority of them never read the food labels. All the selected food items were adulterated ranging from $76 \%$ to 11\%. According to Srilakshmi, 2001 lead is a toxic element and its contamination with food cause nausea, abdominal pain, anaemia, brain damage etc. mercuric salts found in fish is most toxic. It effects the brain. According to "The Hindu, Life \& Style>>Food, July 13, 2010," Danger lurks in the packaged food we find on kitchen shelves. Profiteers routinely adulterate food items like milk, dal, ghee, honey and so on. In recent years, food adulteration has evolved into a very profitable business, causing serious health hazards. Some can even cause cancer. The Hindu, Monday, Jul 20, 2009, Tamil NaduChennai, "A chunk of the green leafy vegetables sold in Chennai is found to contain toxic metals that have the potential to harm various organs of the body. Above studies shows that instead of several food laws, acts, standards there is something lacuna which makes it still prevailing in our daily food items.
\end{abstract}

Key words: Adulteration, Carcinogenic, Hazards, Toxic

\section{Introduction}

In our daily life, we come in contact with dozen of unhygienic and contaminated food products which put really bad effect on our health. Most of these food products just mix up into our daily food and contaminate our health. Even the common food, which we eat, is adulterated. Now a question arises that what is adulteration? An adulterant is a chemical substances which should not be contained within our food, beverage, and fuels. Adulterants may be intentionally added to more expensive substances to increase visible quantities and reduce manufacturing costs, or for some other deceptive or malicious purpose. Adulterants may also be introduced into food products by accidentally or unknowingly. The substance, which lowers or degrades the quality of food material, is called an adulterant.

Adulteration brings a lot of easy money for the traders, but it may spoil many lives. In these days we often hear news related to food adulteration which lead to slow poisoning and various kinds of diseases, and some time it can even result in death. Problem of Adulteration makes the food items used in our daily life unsafe and unhygienic for use. The traders use it for their economic benefit without thinking about its effect on the health of common population of our country, which consumes it.

\section{Incidences of Hazardous Effects of Food Adulteration}

(Sudershan, R. V. et al. 2009) said that food safety in India was about $54.2 \%$ of the respondents did not know or associate diarrohea as a symptom of food-borne disease, while about 50 to $70 \%$ did not know or associate abdominal pain, nausea and vomiting as symptoms of food-borne disease. When asked on storage of food, $75 \%$ reported to leave the cooked food at room temperature and only $29.4 \%$ of them consume the stored food after thorough heating. Only $6 \%$ of the respondents were inclined to complain about food adulteration and others were either ignorant or did not bother about it; $72 \%$ in the same study did not take any action after an episode of food-borne disease outbreak in the village; about $50 \%$ of the respondents did not recognize food spoilage by smell. The findings of this study showed that there is a need to increase awareness pertaining to storage of food, recognition of food spoilage, symptoms of food-borne disease and action to be taken after detecting food adulteration/poisoning. 
It is well known that milk is staple food for both the group of children urban as well as rural area. From both the regions a wide variation of adulterants mixing was observed. The adulterants have been detected by doing the test and it was found that adulteration practice was higher in urban area compared to rural area. Through the household survey of health of children that consumed maximum milk it was found that, the pre school age group from 1-5 years most of the children are dependent on mother's milk, therefore less children have effect on their health related problems like diarrhea and eyesight problems.

About 28\% urban children of age group 6-18 have been affected by headache, while only $4 \%$ rural children were affected of same age group. This percentage increase with the increase in age and $38 \%$ urban children of age group 19-22 were affected by headache, while only $12 \%$ rural children were affected from same age group. Eye sight problem was also detected in survey, and $11 \%$ urban children of age group 1-5 years were affected by eye problems, while only $3 \%$ rural children were affected of same age group while $57 \%$ of urban children age group 19-22 was affected by eyesight problem, while only $16 \%$ rural children were affected of same age group. In the age group 19-22 of total sample 52\% of urban children were affected as compared to only $12.5 \%$ in rural areas. Diarrhoea most often in school going children was one of the major concerns. In age group $1-5$ years, $45 \%$ of total sample in urban area was affected by diarrhoea as compared to only $22 \%$ in rural areas. In the age group 6-18 years, 57\% of total sample in urban children were affected by diarrhoea as compared to only $16 \%$ in rural areas. While in age group 19-22 years, 52\% of total sample in urban children were affected by diarrhoea as compared to only $12.5 \%$ in rural areas. (Singh, Anita; et al. 2011)

According to one survey conducted, adulteration were detected in milk to the tune of $70 \%$ with water, turmeric powder-43\% with chalk powder, red chilli powder-100\% with artificial colour, sugar $37 \%$ with chalk powder etc. (Kumar, Ashish. 2011)

According to National Institute of Nutrition, in India some 4, 00,000 children below five years age die each year due to diarrhoea. Poor hygiene and unsafe drinking water routinely cause illnesses among the poorer classes. Danger lurks in the packaged food we find on kitchen shelves. Profiteers routinely adulterate food items like milk, dal, ghee, honey and so on. In recent years, food adulteration has evolved into a very profitable business, causing serious health hazards. Some can even cause cancer. (The Hindu, Life \& Style>> Food, July 13, 2010)

A chunk of the green leafy vegetables sold in Chennai is found to contain toxic metals that have the potential to harm various organs of the body," said D. Narasimhan, who has pursued research in floristic and plant biotechnology. Adulterations such as foreign leaves added to tea and chemicals added to powdered turmeric have the potential to cause serious health hazards. "Adulteration also happens when food grade chemicals exceed the limit. It causes cancer," said a Corporation health official.

The alleged availability of baby food products in the wholesale market for procurement and illegal packaging as branded products by unlicensed vendors in the central business district is also a cause of concern, says a retailer. "Such practices are illegal and could cause serious health problems for children," said a health official. Label violation is considered as food adulteration, he added. (The Hindu, Tamil Nadu, July 20, 2009)

In $68.5 \%$ Households, wife (home-maker) buys the grocery. Majority of them never read the food labels. All the selected food items were adulterated ranging from $76 \%$ to $11 \%$. Mean percentage of purity was highest in literates $(47.5 \pm 22.48)$ than illiterates and just literates. Food borne illness was prevalent in households with low purity of food. Association was found between per capita income and percentage of purity (0.765).(Khapre,M.P.,2011)

It was found that lead is a toxic element and contamination of food with lead can cause toxic symptoms. As turmeric is coated by illiterate manufacturers in India with lead chromate, lead bring about pathological changes in the kidneys, liver arteries. The common signs of lead poisoning are nausea, abdominal pain, anaemia, insomnia, muscular paralysis and brain damage. Fish caught from water contaminated with mercuric salts contains large amounts of mercury. The organic mercury compound methyl or dimethyl mercury is the most toxic. The effects of methyl mercury are neurological. When the brain is affected, the subject becomes blind, deaf and paralysis of the various muscles make him a cripple.

A survey conducted by the Indian Council of Medical Research (ICMR) also found high levels of pesticide residues in bovine milk and metals arsenic, cadmium and lead in infant formula canned products and turmeric. (Srilakshmi, 2001)

CHENNAI: The issue of adulteration is increasingly threatening a whole range of food products. They range from 'butter biscuits' allegedly made with cheap animal fat in north Chennai to even 'natural' food products.

"A chunk of the green leafy vegetables sold in Chennai is found to contain toxic metals that have the potential to harm various organs of the body," said D. Narasimhan, who has pursued research in floristic and plant biotechnology. 
A variety of green vegetables is grown in marshy areas on Chennai's outskirts. These areas have high levels of industrial pollutants, including heavy metals, which are absorbed by the plants. The harvested leaves find their way to the market at a cheap rate. (The Hindu, jul 20, 2009)

It is common in almost all developing countries. And it's ugly face is come out in the form of it's harmful effects as stomach disorder giddiness and join pain, diarrhea, liver disorder, dropsy, gastrointestinal problems, respiratory distress, oedema, cardiac arrest, glaucoma carcinogenic effects, paralysis etc. in a developing country is at the lowest rung of the development ladder, food adulteration consists of relatively simple measures.

It is found that there are various chemicals and colors used in fruits and vegetables which are very poisonous for health. Calcium carbide used in mangoes, bananas, copper sulphate used to ripen fruits faster, oxytocin a hormone used for faster growth of pumpkin, watermelon, brinjal, gourds, cucumber. Wax adds shine on apples and pears. Cheap green colors containing chemicals such as metallic lead applied to bitter gourd and leafy vegetables to give fresh color. Pesticides \& herbicides used excessively for growing fruits and vegetables. Consumption of chemical-laden fruits and vegetables can prove disastrous for digestive system, eyes and liver. It can also results in vomiting and diarrhea in children, kidney failure. Oxytocin can lead to damage of the brain.

\section{Conclusion}

Adulteration often considered as a one of the major problem of to days life and its ill effects on health from their daily meal item, either, in cereals, pulses, fruits and vegetables or in milk and milk products and spices. The legal enforcement is only one measure for the prevention of food adulteration and it will not have any appreciable impact unless and until there is adequate supply of food at a reasonable price which the average consumer can afford, awareness of the small traders about the food standards which they are expected to maintain, awareness of the common consumer regarding the dangers of adulteration and how to take advantage of the legal machinery to force the traders to get proper food and lastly a sense of honesty among the food traders, big small, in the maintenance of the safety and quality of food.

\section{Reference}

[1]. Kumar A. Tips for detecting the adulteration present in food items. (accessed on 29th nov. 2011 at www.Google.com.

[2]. Srilakshmi, B.,Food Adulteration, Food science, New Age International(P)Limited Publisher, 2001, P.304

[3]. Singh A. et al. (2011) Detection of ill-effect of urea adulterated milk in Varanasi, Food Science Research Journal, 2 (1): $46-49$

[4]. Sudershan R. V. et al. (2009) Food safety research in India: a review, Asian Journal of Food and Agro-Industry. 2 (03), $412-433$

[5]. Khapre MP, et.al, Buying Practices and Prevalence of Adulteration in Selected Food items in a Rural Area of Wardha District: A Cross - Sectional Study, Online Journal of Health and Allied Sciences, vol.10, issue 3: jul.-sep,2011)

[6]. 6) The Hindu, Life \& Style $>>$ Food, July 13, 2010, Be a kitchen detective, Sujata C

[7]. The Hindu, Monday, Jul 20, 2009, Tamil Nadu-Chennai, Adulteration threatens food products, Aloysius Xavier Lopez

[8]. Bagchi K. Prevention of Food Adulteration Some Thoughts. Health and Population, Perspectives \& Issues 7 (3): 167-175, 1984

[9]. Swaminathan G. Home Kit to Detect Food Adulteration. Instruction Manual (accessed on 5 ${ }^{\text {th }}$ jan. 2012 at www.google.com)

[10]. Kumar A. Tips For detecting the adulteration present in food items. ( acessed on $29^{\text {th }}$ nov. 2011 at www.Google.com.)

[11]. Poison in Your Food. (acessed on29th jul. 2012 at www.google.com) 